\title{
A ANÁLISE DE DISCURSO CRÍTICA: CULTURA E FOLCLORE NA NARRATIVA DO BUMBA MEU BOI DE TEÓFILO OTONI (MG)
}

\author{
(The Critical Discourse Analyses: Culture and Folklore in the \\ Bumba-Meu-Boi narrative from Teófilo Otoni-MG)
}

Nádia D. Fernandes Biavati ${ }^{1}$

Universidade Vale do Rio Doce - UNIVALE/MG) Catarina Ferreira da C. R. da Silva ${ }^{2}$ (Pontifícia Universidade Católica de Minas Gerais -PUC/MG)

\section{ABSTRACT}

This article has the objective understands the popular culture and folklore events as discursive event, especially the manifestation: The Bumba-MeuBoi, oriented for a type of social manifestation, constitutive from a knowledge and belief system. In the contemporaneity, there is a culture massification which subordinates manifestations historically built, of popular character, to the marketing dynamic of cultural industry. Then, it is important to think the meaning of this process, like accomplish a critique analysis of narrative speech of this trick, in order to comprehend as interpellated by values and attitudes represented by subjects in a routine marked for the power relations. It's quested in this article, an analysis of this occurrence as a discursive event, through the discursive critique vision from Norman Fairclough (2001).

Key-words: popular culture; folklore; Bumba-Meu-Boi; discourse

1. Mestre e doutora em Linguística pela Universidade Federal de Minas Gerais. Autora de trabalhos publicados na área de Análise do Discurso e na Análise Crítica do Discurso, com interesse nas temáticas de relações de trabalho e trabalhador, trabalhador do ensino e trabalhador migrante, regularidades e regramentos linguísticos. Professora do curso de Letras e do Mestrado Interdisciplinar Gestão Integrada do Território da Universidade Vale do Rio Doce (Univale).

2. Mestre em Estudos Territoriais pela Universidade Vale do Rio Doce/UNIVALE - Governador Valadares. Doutoranda em Linguística e Língua Portuguesa pela Pontifícia Universidade Católica de Minas Gerais/PUC MINAS. Possui trabalho publicado sobre Cultura e Meio Ambiente e Análise do Discurso com ênfase na análise discursiva da narrativa do Bumba-Meu-Boi de Teófilo Otoni. 


\section{RESUMO}

Este artigo objetiva compreender um evento da cultura popular e do folclore como evento discursivo, especialmente o bumba meu boi, orientado para uma forma de manifestação social, constitutiva de um sistema de conhecimentos e crenças. Na contemporaneidade há uma massificação cultural, que subordina manifestações historicamente construídas, de caráter popular, à dinâmica mercadológica da indústria cultural. Assim, torna-se importante pensar o significado desse processo, bem como realizar uma análise crítica de discurso da narrativa deste folguedo, a fim de compreendê-lo como interpelado por valores e atitudes protagonizadas por sujeitos em um cotidiano marcado pelas relações de poder. Busca-se, neste artigo, uma análise desse acontecimento como evento discursivo, através da visão crítico-discursiva de Norman Fairclough.

Palavras-chave: cultura popular; fFolclore; Bumba meu boi;discurso.

\section{Introdução}

O Vale do Mucuri ${ }^{3}$ possui expressivas manifestações culturais folclóricas que precisam ser pesquisadas, uma vez que são poucos os registros encontrados sobre essa temática. É uma região riquíssima em manifestações folclóricas nascidas nos quilombos e nas tribos indígenas. Considerada o principal polo econômico e possuidora de grande parte das manifestações culturais, a cidade de Teófilo Otoni foi escolhida para a análise do evento discursivo: o bumba meu boi.

O objeto de análise deste artigo é o bumba meu boi, evento existente na cidade há pelo menos 26 anos. Para o grupo integrante, o bumba meu boi representa muito mais que uma simples festa ou uma simples dança. É uma história que presentifica as relações sociais de uma época, tornando-se, desse modo, um evento discursivo. A narrativa do bumba inspirou outra festa muito importante para a cultura brasileira: a de Parintins (PA), dos bois Garantido e Caprichoso, que alcançou ampla divulgação por causa do auxílio midiático, o que não ocorre com a festa do boi de Teófilo Otoni (MG), e da sua adequação (práticas sociais e discursivas) à sociedade a que se apresenta.

3. Composto pelas microrregiões de Teófilo Otoni e Nanuque (IBGE, 2000). 
Este artigo leva a algumas reflexões acerca deste evento: Em que medida o evento discursivo do bumba meu boi colabora para as expressões culturais do território de Teófilo Otoni? Quais são as práticas representadas e reafirmadas por meio do bumba de Teófilo Otoni e quais são os valores e os sistemas de conhecimentos e de crenças disseminados a partir desse evento discursivo no território simbólico de Teófilo Otoni?

O olhar interdisciplinar proposto pela análise de discurso crítica (ADC) engloba elementos relevantes à análise do texto, como análise literária e como aspectos semióticos, pertinentes à filosofia, à antropologia e à sociologia. Eles permeiam os caminhos ou o caminho por onde qualquer gênero textual passa ou se constrói. ${ }^{4}$

Os estudos que hoje se baseiam na ADC estão diretamente ligados a compreender os problemas sociais e apontar soluções (se for possível) para eles. No caso do objeto deste artigo, o problema social evidenciado se relaciona à massificação cultural, ${ }^{5}$ especificamente a partir da história do bumba meu boi contada em Teófilo Otoni (MG).

\section{A ADC: um olhar possível para as manifestações populares}

A análise de discurso crítica é um termo estabelecido por Norman Fairclough, uma expressão que surge em um artigo publicado em 1985 no periódico Journal of Pragmatics. Pode-se dizer que é uma continuidade dos estudos da linguística crítica desenvolvidos na década de 1970, na Universidade de East Anglia (cf. RAMALHO; RESENDE, 2006, p. 20). Hoje é considerada uma abordagem interdisciplinar de

4. Os estudos críticos do discurso floresceram na Europa em 1991 (Critical Discourse Analysis - CDA) e chegaram ao Brasil, em 1993, pelo trabalho pioneiro de Izabel Magalhães, com a sigla de ADC, o que marca o grupo de Brasília (cf: Silva e Ramalho, 2008: 266).

5. Essa massificação pode provocar o isolamento daquele sujeito que não a acompanha, dentro de um propósito capitalista da produção em série de expressões culturais, que objetiva também o lucro. 
estudos e apresenta caráter metodológico, possibilitando perspectivas para a análise de eventos culturais como o bumba meu boi.

Atentando para a análise crítico-discursiva, o olhar textualmente orientado se torna uma estratégia para o estudo do bumba meu boi. Essa discussão acontece a partir da visão da narrativa do folguedo, tendo como base as três perspectivas sobre os significados do discurso - a acional, a representacional e a identificacional —, perspectiva de análise orientada por Fairclough $(2003 ; 2006)$, que também caminha ao encontro de interpretações dos fatos sociais, culturais, levando-se em conta que essa forma de análise indica o olhar às questões contextuais que permeiam o evento narrativo do folclore, construído um local, sob os frutos de sua história. Essa análise se junta à concepção de folclore, de cultura popular e de tradição, sob um olhar transformador e socializador.

O significado acional na análise crítica discursiva aborda os gêneros discursivos como processos que manifestam o uso da língua no dia a dia. Eles interligam o caminho da oralidade com a escrita, sob o mesmo viés da linguagem, como práticas sociais (MARCUSCHI, 2010), interessantes de ser percebidos na perspectiva de observação ao significado identificacional, em observação ao estilo de como a narrativa é construída e disseminada socialmente. Ao se trabalhar o significado acional do bumba meu boi enquanto gênero discursivo, percebe-se a relação entre evento discursivo e prática cultural, passível de ser observada como acontecimento, uma forma de relato, de dança de personagens que compõem esse gênero discursivo, que é nomeado e difundido como folguedo.

A ADC considera os gêneros como dinâmicos, em movimento. Sua inter-relação com a ação semiótica os tira do lugar ocupado, há até algumas décadas, como molduras de um texto, em que se podia enquadrá-los em suas características, sem observar sua relação com o meio e com os fatores socioculturais ali envolvidos.

Nesse sentido, o significado acional referenda que os discursos estão ligados diretamente às práticas sociais. Já o significado representacional surge da observação do modo como atores sociais são representados, indicando posicionamentos ideológicos em relação 
a eles e a suas atividades. Muitos desses atores sociais podem aparecer em determinados discursos, sob julgamento do que são ou do que fazem. Por exemplo, julgamos os posicionamentos das personagens do bumba meu boi em sua narrativa, uma vez que indicam reflexos de personagens e de posicionamentos sociais de trabalhador e patrão sobre determinado acontecimento que cerca o boi. Por fim, o significado identificacional permite uma reflexão sobre o tipo de identidades construídas pelo grupo do folguedo de Teófilo Otoni sobre a condição do empregado e do fazendeiro no decorrer do acontecimento em que o boi é envolvido.

Sabe-se que os estudos da análise crítica do discurso não se limitam ao trabalho de Norman Fairclough (2001; 2003), mas neste artigo utilizam-se suas ideias como base para a análise da história do bumba meu boi, uma vez que a análise crítica do discurso propõe a abordagem crítica para "o estudo linguístico discursivo de textos no sentido de que as pesquisas vinculadas [...] assumem uma posição explícita em face de problemas sociais parcialmente discursivos, isto é, não simulam 'imparcialidade científica”' (RESENDE, 2009, p. 12). Destaca-se, primordialmente para este artigo, a versão da narrativa do bumba, contada por cidadãos da cidade de Teófilo Otoni (MG):

A mulher do capataz desejou comer o fígado do boi do 'sinhô' da fazenda. Esse boi aparecera há pouco tempo nessa fazenda. A mulher do capataz - Catirina, que estava grávida, ao ver o boi, desejou logo comer o seu fígado. Ela, então, disse ao marido que, se ele não o matasse, ela perderia o menino. E o capataz disse:

- Ave Maria, se eu mato aquele boi!

Porém, o 'sinhô' da fazenda estimava demais o boi. Mas, mesmo assim, o capataz ainda foi conversar com seus companheiros, os outros escravos para ouvir a opinião deles. E os outros escravos perguntaram como seria se a esposa dele não comesse o fígado. Ela perderia o menino? Ele deixaria isso acontecer?

Então, o capataz pegou o boi e o matou.

Quando o dono da fazenda deu por falta do boi, ficou num morrenão-morre de tristeza. E o capataz pegou a esposa e foi-se embora da fazenda. Anos se passaram, a criança nasceu, cresceu, e seus pais morreram. O menino, que agora era homem, resolveu voltar à fazenda onde os pais um dia trabalharam. O 'sinhô' ainda estava vivo, 
mas muito velho. A carcaça do boi ainda se encontrava na fazenda, e o rapaz resolveu pegá-la, comprou um pedaço de pano muito bonito e chitado e fez aquela capa na carcaça do boi e foi fazer graça e dançar para o velhozinho. Então, ele se alegrou, não viveu muitos anos não, mas morreu alegre. Tinha visto o boi que ele achou que tinha morrido. ${ }^{6}$

Algumas reflexões feitas neste artigo passam por questões colocadas no âmbito das relações sociais. Portanto, estão sujeitas a diferentes maneiras de interpretação e de compreensão.

Por meio de uma análise crítico-discursiva é possível uma gama de interseções entre as ideias de autores, que discutem a cultura de massa, o folclore, a cultura, tradição e o discurso como representações discursivas, transformadas em um produto de consumo, em diferentes formas de divulgação, que nem sempre se tornam um movimento de fácil observação e discussão.

Para tanto, tenta-se fazer uma divisão em três momentos que de certo modo se complementam em seus argumentos. Segue-se um caminho do olhar crítico, uma vez que o folguedo é tratado como prática sociocultural, discursiva, política e como movimento ligado a uma construção sócio-histórica das manifestações populares. Já que uma investigação discursiva crítica propõe um olhar ao contexto como crucial, relacionam-se os aspectos narrados aos valores da moral socialmente instituída e da família. Nesse sentido, são relevantes as questões discursivas, como a investigação de contextos e de textos: a análise da narrativa no contexto da história do Brasil e sua relação com a mídia, com a cultura de massa e com a própria comunidade — indicando importante contribuição de referencial metodológico de análise para eventos discursivos, atribuindo-lhes sentidos econômicos, históricos e sociais ao descrever, interpretar e explicar como as relações

6. Relato coletado do grupo de Folia de Santos Reis e Imaculada Conceição de Teófilo Otoni (MG), para a pesquisa da FAPEMIG, intitulada Diagnóstico das manifestações culturais da microrregião de Teófilo Otoni, desenvolvida entre os anos 2007 e 2009 pela autora da dissertação Discurso e folclore em o bumba meu boi: Teófilo Otoni também tem o boi!, Catarina Ferreira da Conceição Rodrigues da Silva. 
sociais nos processos discursivos desvelam valores, crenças e práticas de um povo.

\section{Cultura, tradição e território}

A cultura e a tradição estão em movimento na sociedade à qual se inserem; caso contrário, morrem, desaparecem em um mundo capitalista. Paradoxalmente ainda há espaço para expressões culturais mantidas há séculos com suas narrativas que não foram influenciadas pelos contextos econômicos, sociais, locais e nacionais contemporâneos. Da mesma forma, há espaço para expressões folclóricas acompanhadas pela cultura de massa.

Todos os eventos folclóricos se misturam cotidianamente à vida das pessoas e contribuem para a formação de uma identidade cultural local, orientada para os eventos globais, visto que seguem os rumos dos eventos do território brasileiro.

O conceito de cultura não se define apenas como algo aprendido e reaprendido, de forma estática e sem reflexão por parte dos sujeitos. Seu conceito evolui, se apresenta e se reconstrói ao longo da construção da história do homem, da sua movimentação dentro dela e das suas relações sociais e, por que não dizer, econômicas.

Algumas histórias são compartilhadas e repassadas oralmente, de geração a geração. Ali está a estratégia da tradição: a repetição. Ironicamente dessa maneira, as mudanças serão inevitáveis, pois o fato de se passar ou se reinventar uma história oral tornará essa forma textual sujeita às mudanças de uma época ou de um contexto social ou político. Aqui, se tem a clareza sobre o novo significado da cultura e da tradição para a vida social e sobre o processo de massificação sofrido na contemporaneidade, como um processo que cruza com a cultura construída ao longo dos séculos e uma que se (re)constrói com a ajuda de novos elementos de uma sociedade contemporânea e suas demandas em um sistema capitalista.

Na comparação com o movimento de Parintins, percebese que o folguedo se reinventa, pois é divulgado e fomentado pelo 
Estado e pela mídia, tomando muitas vezes proporções nacionais pela competição entre bois. Em Teófilo Otoni, ao contrário, ele ainda não se reinventou, ainda tem pouca força; é acreditado por poucos e pouco divulgado pela mídia local. Em movimento contrário, se mostra repleto de diálogos híbridos, cheios de sentidos, trazendo as tensões dos discursos familiares e econômicos, as identidades do patrão e do empregado representados no evento discursivo, tomado em seu significado acional.

Parte-se, então, da ideia de que a cultura construída cotidiana e historicamente pelos sujeitos que ocupam determinado território. O próprio homem constrói o seu território e a sua cultura a partir de suas representações, seus discursos, suas relações e suas necessidades. O território e sua delimitação nem sempre acontecem de forma material: podem ser somente imaginários, atuando no campo simbólico.

O bumba meu boi, sob o foco da renovação de alguns conceitos importantes para os estudos sobre expressões culturais, de cultura e folclore, constrói uma nova forma de pensar esses conceitos. Nessa direção, a ideia dos conceitos de cultura, folclore está associada às mudanças históricas, econômicas, sociais e culturais de uma sociedade ou comunidade, junto ao sujeito visto como integrante dela. Dentro de uma nova concepção mundial do significado da cultura na sociedade, as expressões culturais se atualizaram, transformando também tais conceitos.

O evento do bumba meu boi, sob o enfoque dos estudos críticos do discurso, destaca o posicionamento micro e macrotextual da narrativa, a partir do olhar de Norman Fairclough (2001; 2003) sobre três novas perspectivas dos significados da linguagem: acional (gênero), representacional (discurso) e identificacional (estilo). Nesse sentido, a proposta de estudo do contexto para o texto visou compreender os três significados que perfazem o evento discursivo do bumba e sua relação com o evento do bumba meu boi de Teófilo Otoni.

Nota-se, portanto, que o significado acional se compõe da verificação de que o folguedo corresponde ao evento como um 
todo, com história, dança, paramentos, personagens e dizeres. O significado representacional garante importância aos discursos das relações de classes na composição da narrativa. Nele as instituições do trabalho e da família marcam as territorialidades simbólicas que definem, inclusive, as ações dos personagens representados enquanto identidades de patrão, empregado, marido, mulher, colegas de trabalho e figura mítica do boi. A narrativa toma evidência quando se coloca o olhar no texto e no plano do contexto.

O evento do bumba meu boi se configura como um significado identificacional (estilo próprio) que enriquece e valoriza a cultura no âmbito da arte e da história nacional. Em sua narrativa se refletem visões de um todo global e local da construção das relações sociais através das suas práticas, seja social, de trabalho, de poder, da família e de trabalho de um território nacional; seja discursiva na sua forma peculiar de consumo e de divulgação em momentos distintos, de forma ora individual, ora coletiva, seja na literatura, seja na sua forma alegórica de apresentação, em suas festas, seja em Teófilo Otoni, seja em Parintins, com seus participantes e seus personagens, suas vestimentas, suas bandeiras e suas fitas.

O bumba é carregado de sentidos e interpelado por ideologias. Constitui-se como ação que se desenvolve num território, ou seja, é territorialidade que se reveste do exercício sutil do poder exercitado pelos discursos circulantes no folguedo. Por meio de seu evento se disseminam valores trazidos de outras vivências, construídos por relações sociais específicas de outro tempo e de outro lugar; embora se atualizem e permaneçam até os dias de hoje.

A representação discursiva embasa uma discussão a partir dos referenciais de estudos de Fairclough $(2001$; 2003) sobre o texto, a prática discursiva e a prática social. Propõe uma investigação sobre as relações culturais advindas desse evento como parte de uma identidade pertencente à tradição popular reinventada ao seu modo, em um território geográfico específico.

Neste artigo, ao se considerar que as funções da linguagem são algo que vai além do auxílio ao ato de comunicar, um novo objetivo surge: demonstrar a dinâmica das relações sociais e discursivas, a partir 
do estudo sociossemiótico do cotidiano em determinado território. No caso, a discussão traz as festas e as danças folclóricas demonstradas nos contextos de seus territórios geográficos, em uma dinâmica que implica percepção da forma simbólica, na qual podem se apresentar as relações de poder em uma época ou em um lugar.

Deve-se acrescentar aos fatores que conceituam o termo cultura, as crenças, os comportamentos, os valores, as regras, a moral e os costumes de determinada sociedade, que podem ser apreendidos e aprendidos dentro de uma família, uma comunidade ou na própria relação com a sociedade. Dessa maneira, ao pensar a cultura, devese entendê-la como um fenômeno social, e não meramente como imposição de um sistema. A construção de seu discurso configura um lugar, como um conjunto de vivências, dentro de um território, parte da vida social de uma comunidade.

Uma reflexão sobre cultura e cultura de massa, relacionando o bumba meu boi de Teófilo Otoni (MG) e o de Parintins (PA) não mais reflete a ideia de que a cultura de massa resulta em uma alienação dos indivíduos, mas que ela serve para uma discussão sobre a necessidade de renovar alguns grupos folclóricos, a fim de que não morram na sociedade do século XXI.

O bumba de Teófilo Otoni pode ser condizente com a manifestação cultural típica da modernidade, híbrida em sua origem e em seu modo de ser e de fazer culturais. Ao se relacionar esse evento às ideias de Fairclough $(2001 ; 2003)$, ratifica-se que qualquer evento discursivo pode ser considerado texto, prática discursiva e prática social. Portanto, as narrativas provindas de expressões folclóricas, carregam nos seus elementos sociossemióticos indicações culturais e sociais, ricas de informações para o entendimento da construção da sociedade brasileira e das relações que orientam essas práticas. Além disso, a narrativa do bumba se relaciona aos estudos discursivos, porque diz respeito aos aspectos contextuais (no nível do significado acional), que sustentam e norteiam a narrativa, constituindo, dessa maneira, o evento do boi. 


\section{Metodologia de análise}

Seguindo a proposta da análise do discurso crítica do bumba meu boi, destaca-se como importante a investigação dos sentidos que norteiam o folguedo. Desvelando-se as conexões e as causas ocultas de sua construção, ou seja, os três sentidos/significados que marcam a investigação discursiva, conforme a visão dos estudos de Fairclough (2001; 2003), especialmente aqueles formulados com base no realismo crítico, de Bhaskar, orientados para a percepção da realidade originando efeitos nos domínios da vida social. Um outro aspecto importante para a análise textualmente orientada é um conjunto de significados estudados na linguística sistêmico-funcional de Halliday - os significados acional, representacional e o identificacional. A partir de uma visão crítica de estudos da linguagem postula-se: construir uma assimilação entre as funções da linguagem (discussão iniciada na linguística sistêmico-funcional (LSF) e continuada com novas propostas de agrupamento por Norman Fairclough, 2001; 2003) e o texto (função e meio de divulgação do evento do bumba meu boi de Teófilo Otoni). O primeiro passo é desvendar o significado acional (que constitui o evento como gênero discursivo, atividade ratificada socialmente, norteado por uma conjuntura); o representacional (que destaca o evento do bumba como perpassado por discursos); e, finalmente, o identificacional (reconhecido por meio da investigação dos estilos na narrativa), completando a proposta de um estudo comprometido eticamente, conforme postulado na obra de Fairclough (2001; 2003; 2006), e observado por Resende e Ramalho (2006, p. 22): “...desde o início, a ADC visava a contribuir tanto para a conscientização sobre os efeitos sociais de textos como para mudanças sociais que superassem relações assimétricas de poder, parcialmente sustentadas pelo discurso".

Observa-se a representação discursiva como um foco para investigar o folguedo seja como prática discursiva concentrada na produção, na distribuição e no consumo do evento do bumba, seja como prática social, pois sua orientação acontece voltada para a disseminação de identidades, práticas e atitudes representadas a 
partir da história que cerca o folguedo. Propõe-se uma investigação sobre as relações culturais advindas desse evento como parte de uma identidade pertencente à tradição popular reinventada a seu modo, em um território geográfico específico.

Fairclough (2001) propõe um diálogo entre as teorias sociais na análise de discurso textualmente orientada, com o intuito de construir um quadro teórico-metodológico pertinente à perspectiva crítica de linguagem como prática social. $\mathrm{O}$ autor valoriza primeiro a visão científica de crítica social; depois o campo da pesquisa social crítica na modernidade tardia; e, por último, a teoria e a análise linguística e semiótica.

As expressões culturais, mais especificamente, o bumba meu boi, são repletas de informações. Através de seus símbolos, formam um modo de significar a experiência, discursivamente construída. Além disso, as diferentes formas de linguagem e suas funções produzem um texto com especificidades e objetivos dentro da sociedade em que transitam.

\section{O bumba meu boi: contextos históricos socioculturais do Brasil}

Um estudo discursivo sobre o bumba meu boi prevê antes de tudo uma análise da conjuntura do país, entendida como a compreensão do modo como se dá a configuração das práticas das quais o discurso - linguagem como prática social em análise - é parte das práticas sociais (cf. RAMALHO; RESENDE, 2009).

O Brasil guarda características híbridas ainda em formação. Entram em discussão não só os costumes de uma colonização europeia mas também elementos de seus primeiros habitantes, os índios, que influenciaram e influenciam as práticas culturais até os dias de hoje. Considera-se também nesse hibridismo um conjunto de elementos trazidos pelos africanos, que, embora tenham sido oprimidos, deixam claras suas marcas por meio de valores e de práticas sociais e discursivas. 
Nos estudos folclóricos, aparece uma gama de informações históricas e, através de diferentes linguagens, pode desvendar formas distintas de relações sociais, que influenciaram a construção histórica no Brasil, ao longo do tempo.

Atualmente uma nova luz sobre o conceito de folclore permite um olhar atento de suas histórias, envolvendo o global, e não exclusivamente o local. Ele é resultado das relações sociais construídas e arraigadas dentro de um sistema econômico, que sempre buscou se basear no modelo capitalista e dar força para que ele se consolidasse. O folclore não mais é visto como "exclusivo da classe social mais baixa, mas sim de todos os habitantes de um país ou de membros de uma comunidade" (FERNANDES, 2003, p. 255). Portanto, com a influência de outras culturas, ele traz importantes dizeres que traduzem a história nacional.

Nesse sentido, refletir sobre o discurso com base nas ideias do linguista Norman Fairclough (2001; 2003; 2006) é oportuno, na medida em que por meio dele é possível perceber o folguedo inserido em uma realidade relacionada à conjuntura que deve ser observada, ou seja, a tradição que perde e toma força conforme os contornos sociais do evento do bumba.

Desse modo, o folguedo é passível de investigação, como evento que, de um lado, se relaciona com as realidades sociais da força midiática e, de outro, luta para sobreviver em meio a uma realidade. É importante unir análise de texto e contexto, e destacar o evento a partir de uma análise textualmente orientada.

É conveniente observar também que, para os estudos críticos do discurso, vários autores, entre eles Fairclough (2001; 2003; 2006), não separam mais contexto social de produção textual. Novos rumos são tomados, atualizando e contextualizando os textos na sua esfera social. Os estudos críticos do discurso, portanto, são uma abordagem ligada aos estudos linguísticos e um avanço em relação a eles, pois se trata de uma abordagem interdisciplinar, cuja proposta é compreender o discurso na prática social.

A história do boi, assim como a apresentação, os paramentos, os personagens, as pessoas como parte de um grupo, devem ser vistos 
como elementos das diferentes áreas formadoras de uma consciência histórica, crítica e social, vinda e desenvolvida pelas ciências sociais, pelos estudos culturais e por meio da linguística.

Para Fairclough (2006), todo texto possui elementos que remetem às práticas discursivas e, principalmente, às práticas sociais. De acordo com o autor, deve-se valorizar o que as outras áreas do conhecimento têm a oferecer ao entendimento do texto analisado, seja para desvendar o contexto (práticas discursivas), seja para compreender as ideologias e o poder (práticas sociais), seja para relevar os elementos léxico-discursivos (texto).

Entende-se o bumba meu boi como um evento discursivo, conforme a visão crítica dos estudos da linguagem, ${ }^{7}$ porque é uma expressão cultural que se constitui enquanto texto (atividade oral), enquanto prática discursiva (de produção, distribuição e consumo de discursos) e enquanto prática social (que se revela no fazer de um grupo, como expressão de marcas identitárias, de discursos na representação de práticas e valores que circulam socialmente). Seu texto leva ao entendimento de algumas práticas que fizeram e ainda fazem parte da história do Brasil: as relações de poder entre patrão e empregado; esposo e esposa; mídia e sociedade.

Dentro da análise crítica do discurso, as categorias e os termos utilizados têm seu significado entendido como uma rede de sentidos que orientam a construção do evento discursivo, reformulado a partir de uma nova forma de ver e de contextualizar a sociedade atual. Sobre esse significado, coloca-se:

Ele explica que o discurso figura de três principais maneiras como parte de práticas sociais, na relação entre textos e eventos: como modos de agir, como modos de representar e como modos de ser. A cada um desses modos de interação entre discurso e prática social corresponde um tipo de significado. (RAMALHO; RESENDE, 2006, p. 60).

7. Os estudos críticos da linguagem correspondem aos estudos discursivos desenvolvidos pela análise crítica do discurso (ADC), vertente preocupada com os estudos da linguagem como prática social. 
Considerando textos como modo de agir, de representar e de ser, cada um dos três significados, focaliza o evento sob diferentes aspectos, levando em consideração sua relação com a esfera social e por onde e como transita o seu texto. Desse modo, a linguagem representa o mundo externo (seus objetos, seus eventos, suas práticas) e interno (as crenças, os valores e os desejos) (RAMALHO; RESENDE, 2006).

A visão do dono do boi perdido prevalece como a mais forte, ainda que seja desafiado pela prática do empregado que the toma o boi. Embora a narrativa seja feita a partir do olhar do escravo, suas atitudes demonstram a força da voz do patrão em sua vida, já que há a preocupação em resolver o problema pelo filho. $\mathrm{O}$ dito, ou melhor, o não dito pelo escravo na narrativa do bumba meu boi, é o que de fato representa uma realidade histórica - caso seja analisada dentro de um contexto: o final do século XVIII e o início do século XIX.

$\mathrm{O}$ fato de a narrativa do boi se constituir da atuação dos personagens não quer dizer que exista uma abertura ao diálogo entre as classes sociais, nem um espaço para que se expliquem seus atos e se expressem os reais conflitos.

As únicas vozes de poder ouvidas na narrativa são a da esposa - ansiosa para comer o fígado do boi, o que representa um estado de poder pelo fato de estar grávida: "A mulher do capataz, Catirina, que estava grávida, ao ver o boi, desejou logo comer o seu fígado. Ela, então, disse ao marido que, se ele não o matasse, ela perderia o menino"s, - e a voz do dono da fazenda, que demonstra o viés da dominação a partir do poder de controlar uma vida: "E o capataz disse: - Ave Maria, se eu mato aquele boi!".

Quando o dono da fazenda deu por falta do boi, ficou num morre, não morre de tristeza. E o capataz pegou a esposa e foi-se embora da fazenda. Anos se passaram, a criança nasceu, cresceu, e seus pais morreram. $\mathrm{O}$ menino, que agora era homem, resolveu voltar à fazenda onde os pais um dia trabalharam. $\mathrm{O}$ 'sinhô' ainda estava vivo, mas

8. Trecho da narrativa contada em Teófilo Otoni e descrita na dissertação Discurso e Folclore em O BUMBA-MEU-BOI:

Teófilo Otoni também tem o Boi!. Relato retirado da pesquisa realizada pela autora entre os anos 2007 e 2009. 
muito velho. A carcaça do boi ainda se encontrava na fazenda, e o rapaz resolveu pegá-la, comprou um pedaço de pano muito bonito e chitado e fez aquela capa na carcaça do boi e foi fazer graça e dançar para o velhozinho. Então, ele se alegrou, não viveu muitos anos não, mas morreu alegre. Tinha visto o boi que ele achou que tinha morrido. ${ }^{9}$

A dinâmica da dominação se torna clara na narrativa de Teófilo Otoni, quando o escravo foge da fazenda do patrão, levando consigo toda a sua família e, em outro momento, quando o filho do escravo passa uma vida pensando em se redimir do ato cometido pelo pai.

Aí foi [...] o patrão dele [...] tava morre 'num' (sic) morre. O menino foi crescendo, esse menino cresceu, cresceu e lá um belo dia, eh! O pai dele, a mãe dele morreu. Aí foi, ele voltou pra essa fazenda, quando ele voltou pra essa fazenda, esse homem ainda era vivo, mas já bem 'veizin', o 'sinhô' deles ainda era vivo, né? [...] aí, o que ele fez. Quando ele chegou, a carcaça do boi tava lá... que ele fez? Ele foi, 'pegô' a carcaça do boi, 'comprô' um pano muito bonito, um pano chitado e fez aquela capa na carcaça e foi fazer graça pro 'veio', o patrão do pai dele, né? E 'chegô' lá com esse boi tampado, minha 'fia'! [...] e foi fazer graça e dançar. Aí esse homem alegrou — num viveu muitos anos não, mas ainda morreu alegre, né? Tinha visto o boi, a carcaça. Achou que tinha morrido...

Como sugere Fairclough (2006, p. 90), a linguagem pode ser uma prática social, e não algo individual: "O discurso implica ser um modo de ação, uma forma em que as pessoas podem agir sobre o mundo e especialmente sobre os outros, como também um modo de representação". Portanto, a narrativa do bumba e os discursos dos personagens demonstram o papel que cada um representa na história e na construção da sociedade brasileira — a partir de uma reflexão interdisciplinar que pode refletir nos campos da análise literária, da semiótica, da filosofia, da antropologia e da sociologia.

A investigação discursiva do evento bumba meu boi leva em conta sua história, sua figura e a própria dança, "a prática discursiva é constitutiva tanto de maneira convencional como criativa: contribui para reproduzir a sociedade, identidades sociais, relações sociais,

9. Idem. 
sistemas de conhecimento e crença como é, mas também contribui para transformá-la" (FAIRCLOUGH, 2001, p. 92). Dessa forma, tendo em vista essa condição reprodutiva e criativa do discurso, a manifestação do bumba meu boi foi escolhida, neste trabalho, devido a sua importância para a cultura brasileira. Além disso, dentro de sua narrativa ela contém aspectos literários e semióticos (dança, teatro, música e cores) que refletem crenças, valores, práticas e mitos de um povo em seu território.

\section{Passando a lupa no evento do bumba meu boi}

Estas reflexões se concentram em um viés antropológico, que garante subsídios para um estudo do texto do bumba a partir do evento discursivo: texto, prática social e prática discursiva. Os discursos compõem as relações sociais na narrativa. Nesse sentido, se fazem a partir das instituições que o cercam como discursos: da família, do trabalho, das relações desiguais de poder entre patrão e empregado no campo rural, do respeito e do medo do empregado pelo patrão, da questão moral do filho do empregado, que volta para alegrar o dono da fazenda com um pedido de desculpas, etc.

A dança, a representação de personagens e o desenrolar da narrativa resultam em um evento discursivo. Nele se delineiam os usos da linguagem, pautados como texto em narrativa oral; e a prática discursiva, como as formas de produção, de circulação, de distribuição e de consumo desse evento visto como produto. Ele se liga, por fim, a outras orientações de práticas culturais, passíveis de estudos na atual ordem do discurso, mais mercantilizadas e voltadas para os eventos surgidos das relações capitalistas no âmbito rural.

A prática social é descrita como uma dimensão do evento discursivo, assim como o texto. Essas duas dimensões são mediadas pela prática discursiva, que focaliza os processos sociocognitivos de produção, distribuição e consumo do texto, processos sociais relacionados a ambientes econômicos, políticos e institucionais particulares. A natureza da prática discursiva é variável entre os diferentes tipos 
de discurso, de acordo com fatores sociais envolvidos (RESENDE; RAMALHO, 2006, p. 28).

Cabe observar os aspectos sociais da narrativa do bumba meu boi segundo a ACD, em que o foco recai sobre a observação da conjuntura do evento. Assim, ocorre a percepção do discurso como prática social, numa ótica da análise tridimensional já proposta por Fairclough, em seu livro Discurso e mudança social, traduzido no Brasil, em 2001 e originalmente publicado em 1992 como Discourse and Social Change. Entretanto, mais recentemente Fairclough lança junto com Lilie Chouliaraki um olhar mais direcionado e específico para a análise da prática social de um texto (CHOULIARAKI; FAIRCLOUGH, 1999). O discurso passa a ser visto como um momento das práticas sociais, compatível com o que se quer observar. No caso, o bumba se insere em um contexto de mudanças sociais, em uma sociedade cujas práticas culturais alcançam visibilidade, a partir da mídia em Parintins, ou não alcançam em Teófilo Otoni, simplesmente porque não têm apoio do poder público e da própria população local.

No bailado do boi cabe observar que essa figura imponente e forte demonstra dominação frente ao território onde acontece a dança. Além disso, seus chifres amedrontam e definem o seu espaço. Ele causa medo e admiração porque simboliza na história um boi ressuscitado, que fora importante para o dono da fazenda - personagem que remete à dominação sobre aquele que roubou o animal.

O evento como prática social, prenhe de sentidos e repleto de valores, leva a um pensamento hegemônico de dominação do patrão, que prevalece ao longo do tempo, e de dor rememorada pelo valor de culpa da infração cometida. Vale ressaltar que manifestações como essa constituem e desvelam representação de um território local e global, marcado por relações socioculturais e reafirmado a partir de relações de poder, ainda que essas se configurem sutilmente, dado o caráter de entretenimento da dança. Portanto, nesse evento discursivo aparece a manifestação de poder não apenas do dono do boi, mas do próprio boi, em toda a história — imaginário e nascido do território imaginário imposto pela força do boi. 
Entretanto, argumentaria que, ao produzirem seu mundo, as práticas dos membros são moldadas, de forma inconsciente, por estruturas sociais, relações de poder e pela natureza da prática social em que estão envolvidos, cujos marcos delimitadores vão sempre além da produção de sentidos. Assim, seus procedimentos e suas práticas podem ser investidos política e ideologicamente, podendo ser posicionados por eles como sujeitos (e 'membros') (FAIRCLOUGH, 2001, p. 100).

De forma particular, para cada um dos personagens, a vida é modificada a partir das necessidades demandadas da figura do boi. Tal como a realidade descrita por Fairclough (2001), passível de mobilizar os sujeitos, reafirmando relações de classe e valores como os da subalternidade.

\section{Considerações Finais}

A narrativa do folguedo do bumba meu boi apresenta elementos ricos de símbolos ${ }^{10}$ permeados por discursos no âmbito social, histórico, de crenças e de valores a serem analisados, como: seus personagens e suas ações, a bandeira e o próprio boi.

No contexto dos estudos críticos do discurso propostos pela ADC, a prática social é uma dimensão importante, pois, associando a narrativa ao estudo de uma conjuntura, é possível observar elementos reveladores de uma discussão política, econômica, histórica e sobre questões humanas. Por esse motivo, é um evento ainda hoje tão valorizado, se não o mais valorizado, entre as narrativas folclóricas.

Ao longo deste artigo, reflexões sobre a narrativa do bumba meu boi foram iniciadas, construindo outras reflexões sobre alguns conceitos que ajudam na construção de um discurso. Tais reflexões

10. Termo que designa, no contexto hermenêutico, o modo de funcionamento da linguagem que, por não ser puramente unívoca, suscita uma necessidade de interpretação. São as expressões de duplo sentido, e não a linguagem unívoca, o campo privilegiado da hermenêutica. $\mathrm{O}$ símbolo refere à dupla intencionalidade da linguagem (P. RICOEUR - CI, 285.)

Disponível em: <http://www.fcsh.unl.pt/invest/edtl/verbetes/S/simbolo.htm>. 
confirmam que o a construção do folguedo se dá como um evento discursivo, repleto de aspectos sociossemióticos, passíveis de um olhar pela ADC: a dança, a posição das personagens, a identidade que eles representam, a história e a narrativa são modos de representar uma prática cultural marcada por relações de poder que se estabelecem no território híbrido brasileiro, com as características assumidas em Teófilo Otoni/MG.

O significado de cultura para a vida social e sobre o processo de massificação sofrido na contemporaneidade, como um processo que cruza com a cultura construída ao longo dos séculos, se (re) constrói com a ajuda de novos elementos e de novos sujeitos em uma sociedade contemporânea e suas demandas em um sistema capitalista. Portanto, torna-se relevante a reflexão sobre expressões folclóricas e culturais ligadas a uma tradição popular, como é o caso do bumba meu boi de Teófilo Otoni, e de outras que hoje se renovam em um novo momento de mundo como é o caso dos bois de Parintins.

\author{
Recebido em: abril de 2012 \\ Aprovado em: maio de 2012 \\ nadiabiavati@yahoo.com.br \\ aprende2@yahoo.com.br
}

\title{
Referências bibliográficas
}

FAIRCLOUGH, N. Language and Globalization. New York: Routledge, 2006.

FAIRCLOUGH, Norman. Analysing discourse: textual analysis for social research. London: Routledge, 2003.

FAIRCLOUGH, Norman. Discurso e mudança social. Tradução de Izabel Magalhães. Brasília: Ed. UnB, 2001. 
FAIRCLOUGH, Norman. The Dialectics of Discourse. Revista Textus. 2001a, p. 231-242. Disponível em: <http://www.ling.lancs.ac.uk/profiles/263 > . Traduzido com autorização do autor por Raquel Goulart Barreto. Acesso em: 22 set. 2009.

FERNANDES, Florestan. O folclore em questão. 2. ed. São Paulo: Martins Fontes, 2003.

HALLIDAY, M. A. K. Introduction to Functional Grammar. London: Edward Arnold, 1985.

JÚNIOR PRADO, Caio. História econômica do Brasil. São Paulo: Brasiliense, 2004.

LARAIA, Roque de Barros. Cultura: um conceito antropológico. 18. ed. Rio de Janeiro: Zahar, 2005.

LIMA, Luiz Costa. Teoria da cultura de massa. 6. ed. Rio de Janeiro: Paz e Terra, 2000.

MARCUSCHI, Luiz Antônio. Da fala para a escrita: Atividades de retextualização. São Paulo: Cortez, 2010.

RAFFESTIN, Claude. Por uma geografia do poder. São Paulo: Ática, 1980.

RESENDE, Viviane de Melo; RAMALHO, Viviane. Análise do discurso crítica. São Paulo: Contexto, 2006.

SILVA, Catarina Ferreira da Conceição Rodrigues da. Discurso e folclore em o bumba meu boi: Teófilo Otoni também tem o boi!. 2010. 130 fl. Dissertação (Mestrado em Gestão Integrada do Território- ênfase em Linguagens) Universidade Vale do Rio Doce, Governador Valadares/MG, 2011.

SILVA, D.E.G. e RAMALHO, V. a Análise de Discurso Crítica: representações sociais na mídia. In: Lara, G., Machado, I.L. e Emediato, W. , Análise do discurso hoje. Rio de Janeiro: Nova Fronteira, vol. 2, pp. 265-292, 2008. 
